\title{
A shadow of air within the heart
}

\author{
Ragesh Panikkath MD, DNB, DM, Deepa Panikkath MD
}

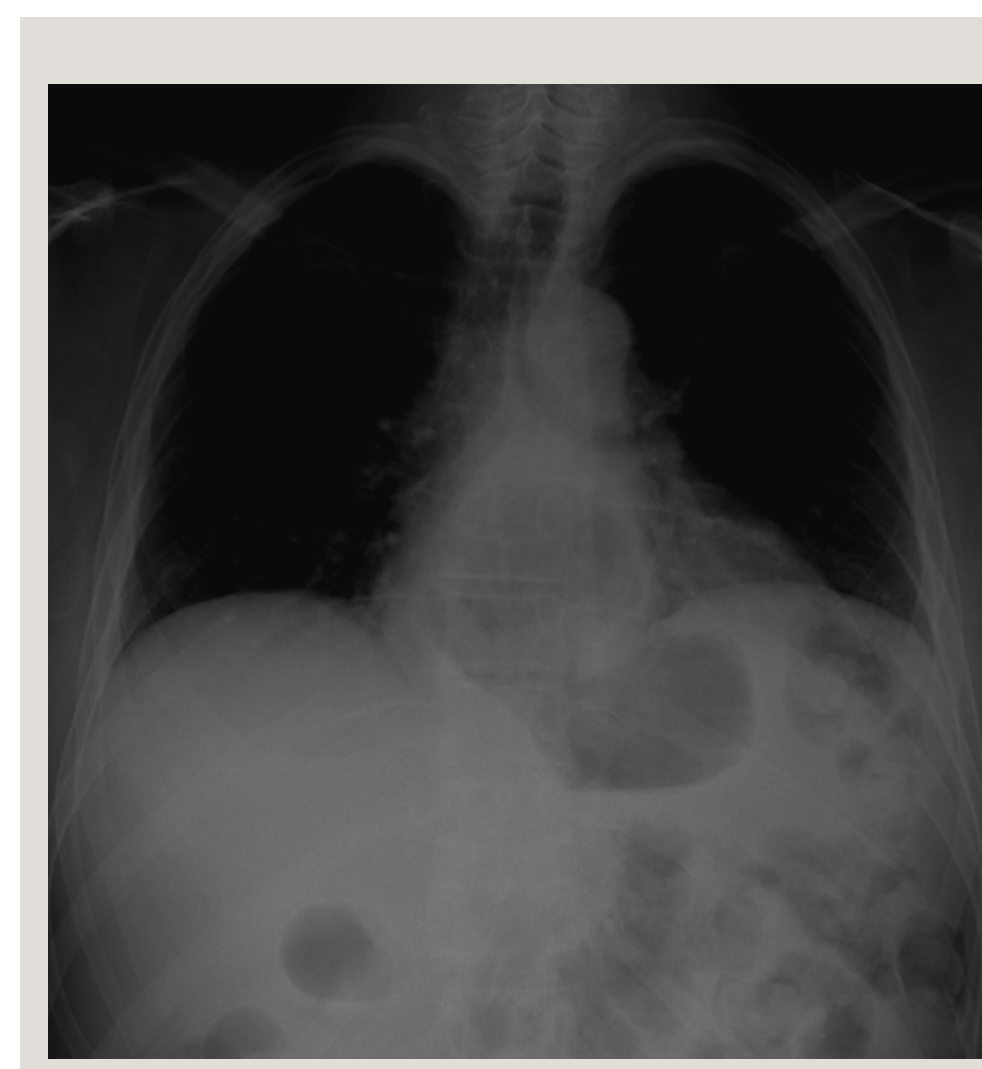

Figure 1 PA chest x-ray shows a radiolucent hourglass shaped shadow due to hiatal hernia within the cardiac border.

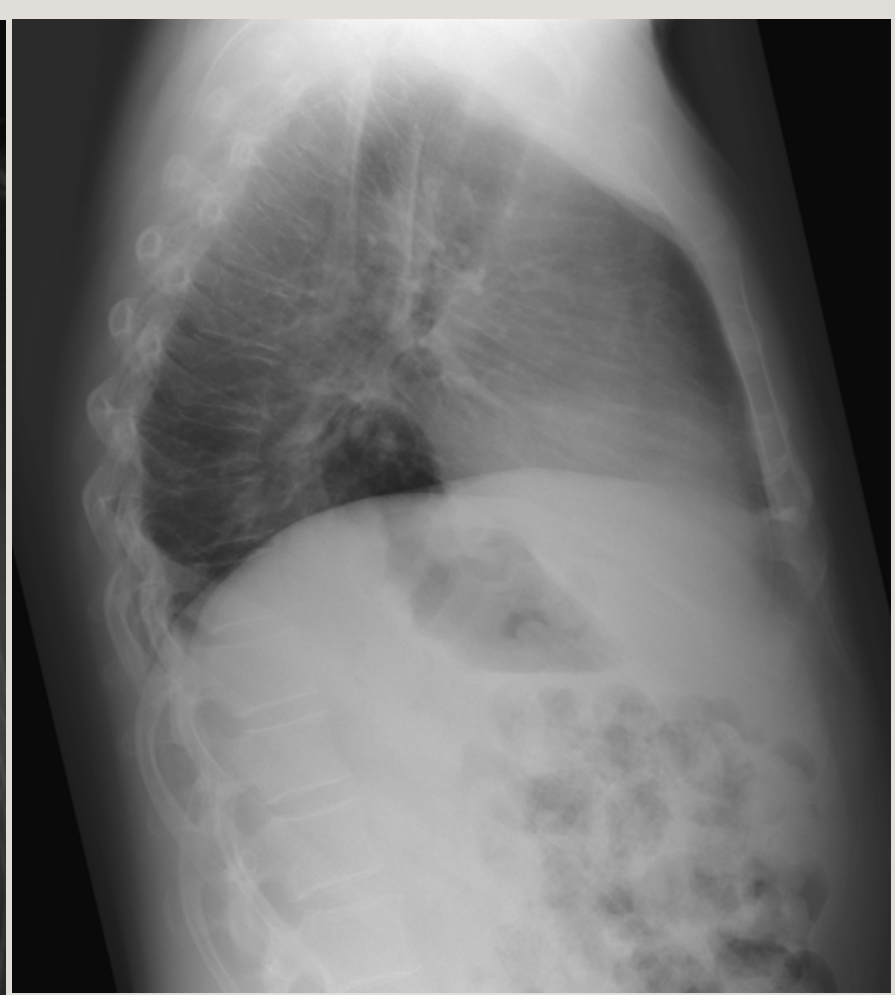

Figure 2 The lateral view of the chest $x$-ray shows the hiatal hernia posterior to the heart.

\section{CASE}

A 55-year-old man presented with fever and productive cough of two days duration. He also had tender cervical lymphadenopathy. His chest $\mathrm{x}$-ray showed a normal cardiothoracic ratio and normal

Corresponding author: Ragesh Panikkath MD

Contact Information: Ragesh.Panikkath@ttuhsc.edu

DOI: 10.12746/swrccc 2014.0207.087 lung fields. However, there was a radiolucent shadow within the cardiac border, continuous with the shadow of gastric bubble with an hourglass shaped constriction in the middle (Figures 1 and 2). This suggested a hiatal hernia in the posterior aspect of the mediastinum, which was more evident in the lateral view. This patient was asymptomatic from the hiatal hernia and was not aware of it. 


\section{Discussion}

A hiatal hernia is the herniation of part of stomach through the esophageal hiatus of the diaphragm. It is more common in females and in older individuals. Although usually asymptomatic, hiatal hernias can cause symptoms such as chest pain, shortness of breath, and palpitations. They may also cause intermittent bleeding from associated esophagitis, erosions (Cameron ulcers), or a discrete esophageal ulcer leading to iron deficiency anemia.

There are two types of hiatal hernia, the sliding and the rolling types. Sliding hiatal hernias are the most common type and occur when the gastroesophageal junction along with a portion of the stomach migrates into the mediastinum through the esophageal hiatus. The lower esophageal sphincter is less effective in the thorax, since it is no longer protected by the positive intra-abdominal pressure. This hernia also causes widening of the esophageal hiatus of the diaphragm and affects the competence of the crura of the diaphragm. These factors explain the predisposition for reflux disease in patients with sliding hiatal hernia. ${ }^{1}$ In the rolling type or paraesophageal type, the lower esophageal sphincter is in the abdomen, but another part of the stomach migrates through the esophageal hiatus into the mediastinum. This type is less prone to reflux disease but may be associated with incarceration. For patients with severe symptoms due to hiatal hernias, surgery, including Nissen's fundoplication, should be considered. ${ }^{1,2}$

Author affiliation : Ragesh Panikkath and Deepa Panikkath are residents in Internal Medicine at TTUHSC.

Submitted: $320 / 2014$

Accepted: 5/17/2014

Reviewers: Cynthia Jumper MD

Conflict of Interest: None

Published electronically: 7/13/2014

\section{References}

1. Garcia-Rinaldi R, Lanza F. Hiatal hernia with severe reflux esophagitis: treatment by superselective vagotomy and Nissen fundoplication. South Med J 1984;77:418-22.

2. Koch OO, Kohler G, Antoniou SA, Pointner R. [Diagnosis and Surgical Therapy of Hiatal Hernia.]. Zentralbl Chir 2014. 